\title{
Reviewing the Structural Features of Autologous Platelet-Leukocyte Gel and Suggestions for Use in Surgery
}

\author{
P.A. Everts ${ }^{a}$ J.J. Jakimowicz ${ }^{b}$ M. van Beek ${ }^{c} \quad$ J.P.A.M. Schönberger ${ }^{d}$ \\ R.J.J. Devilee ${ }^{\text {e }}$ E.P. Overdevest ${ }^{a} \quad$ J.T.A. Knape ${ }^{g}$ A. van Zundert $^{f}$ \\ Departments of a Perioperative Blood Management and ${ }^{\mathrm{b}}$ General Surgery, ${ }^{\mathrm{C} P a t h o l o g y}$ Laboratory, and \\ Departments of ${ }^{d}$ Cardiothoracic Surgery, ${ }^{e}$ Orthopedic Surgery, and ${ }^{\mathrm{f}}$ Anesthesiology, Catharina Hospital, \\ Eindhoven, and ${ }^{9}$ Department of Anesthesiology, University Medical Center Utrecht, Utrecht, The Netherlands
}

\section{Key Words}

Platelet-leukocyte gel · Growth factors • Wound healing • Leukocytes · Antimicrobial activity • Electron microscopic imaging

\begin{abstract}
The therapeutic use of autologously prepared platelet-leukocyte gel (PLG) is a relatively new technology which might stimulate and accelerate soft-tissue and bone healing. The effectiveness of this procedure lies in the exogenous delivery of a wide range of platelet growth factors, intentionally released from autologously prepared PLG. The rationale to employ this technique is to mimic physiological wound healing and reparative tissue processes. Despite an increase in clinical PLG applications, the structures and kinetics of this biological material have not been completely examined. Electron microscopic imaging was performed to evaluate platelet-leukocyte gel structures. Furthermore, directions for PLG application are presented, based on results from published articles in various surgical disciplines. In conclu-
\end{abstract}

This article is part of the thesis of the first author: Autologous Platelet-Leukocyte-Enriched Gel: Basics and Efficacy.

\section{KARGER \\ Fax +4161306 1234 E-Mail karger@karger.ch} www.karger.com

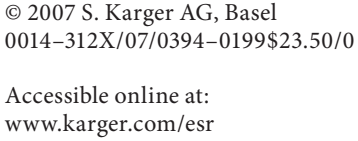

sion, PLG can be useful in a wide range of clinical applications to enhance healing following surgical procedures, since exogenous applied PLG releases instantly platelet growth factors, in the presence of leukocytic cells.

Copyright $\odot 2007$ S. Karger AG, Basel

\section{Introduction}

During the physiological cascades of soft tissue wound healing and bone growth, cellular and hormonal factors have pivotal roles [1], particularly platelet-derived growth factors $[2,3]$. Presently, platelets can be retrieved and isolated from a unit of autologously drawn fresh whole blood. Intraoperatively, point-of-care devices fractionate this autologous blood into platelet-poor plasma, platelet leukocyte-rich plasma (P-LRP), and red blood cells [4]. P-LRP can be activated by (autologous) thrombin to create a viscous solution termed platelet-leukocyte gel (PLG). This platelet coagulum can be exogenously applied as a spray or as a solid gelatinous mass, to soft tissues, chronic wounds, bone, or synthetic bone. The reason for applying PLG to tissues is the delivery of platelet growth factors to mimic and accelerate physiological wound healing and reparative tissue processes $[5,6]$. Although physicians 
Table 1. The most important platelet growth factors

\begin{tabular}{ll}
\hline Platelet growth factor & Function \\
\hline $\begin{array}{l}\text { Transforming growth } \\
\text { factor- } \beta \text {, TGF- } \beta\end{array}$ & $\begin{array}{l}\text { stimulates undifferentiated mesenchymal cell } \\
\text { proliferation; regulates endothelial, fibroblastic and } \\
\text { osteoblastic mitogenesis; stimulates endothelial } \\
\text { chemotaxis and angiogenesis }\end{array}$ \\
\hline $\begin{array}{l}\text { Basic fibroblast growth } \\
\text { factor, bFGF }\end{array}$ & $\begin{array}{l}\text { promotes growth and differentiation of chondrocytes and } \\
\text { osteoblasts; mitogenetic for mesenchymal cells, } \\
\text { chondrocytes and osteoblasts }\end{array}$ \\
\hline $\begin{array}{l}\text { Platelet-derived growth } \\
\text { factor, PDGF-AB }\end{array}$ & $\begin{array}{l}\text { mitogenetic for mesenchymal cells and osteoblasts; } \\
\text { stimulates chemotaxis and mitogenesis in fibroblast/glial/ } \\
\text { smooth muscle cells; regulates collagenase secretion and } \\
\text { collagen synthesis; stimulates macrophage and neutrophil } \\
\text { chemotaxis }\end{array}$ \\
\hline $\begin{array}{l}\text { Epidermal growth factor, } \\
\text { EGF }\end{array}$ & $\begin{array}{l}\text { stimulates endothelial chemotaxis/angiogenesis; regulates } \\
\text { collagenase secretion; stimulates epithelial/mesenchymal } \\
\text { mitogenesis }\end{array}$ \\
\hline $\begin{array}{l}\text { Vascular endothelial } \\
\text { growth factor, VEGF }\end{array}$ & $\begin{array}{l}\text { increases angiogenesis and vessel permeability; stimulates } \\
\text { mitogenesis for endothelial cells }\end{array}$ \\
\hline $\begin{array}{l}\text { Connective tissue growth } \\
\text { factor, CTGF }\end{array}$ & $\begin{array}{l}\text { promotes angiogenesis, cartilage regeneration, fibrosis and } \\
\text { platelet adhesion }\end{array}$ \\
\hline
\end{tabular}

employ PLG applications increasingly, only few data are available on the true content of PLG and the structural changes which occur during the transition from P-LRP to PLG.

This article provides evidence on the ultrastructural changes within PLG, determined by electron microscopic imaging, and shows its clinical use in various surgical areas.

\section{Physiology of PLG}

\section{Platelet Growth Factors}

Peripheral blood is drawn via an infusion catheter into blood bags containing an anticoagulant to prevent the blood from clotting. Thereafter, the predonated blood is sequestered by point-of-care devices into blood components: P-LRP, platelet-poor plasma and erythrocyte concentrate $[4,7]$. P-LRP consists of a small volume of plasma with a high concentration of platelets and leukocytes. These platelets are inactive, and in a liquid form. Generally, the platelet numbers in the PLG are three to seven times higher than normally found in peripheral circulating blood $[8,9]$.

Inside the platelet cytoplasm, $\alpha$ granules and dense granules are present. The $\alpha$ granules contain various platelet growth factors. The most important platelet growth factors are shown in table 1 . However, inactivated P-LRP platelets are nonfunctional, and as a result they do not release their growth factors. The dense granules enclose other platelet substances (like e.g. platelet factor 4, histamine, and serotonin).

To release these platelet growth factors, the P-LRP needs to be activated. When thrombin, a potent platelet activator, interacts with the P-LRP, a sticky platelet aggregate is formed. At this stage the viscous PLG can be applied to wound tissues or bone. Subsequently, the platelets' $\alpha$ granules release their growth factors into the extracellular milieu. In this environment they might bind to specific platelet growth factor receptors present in wound tissues. Released growth factors interact and bind with the platelet tyrosine kinase receptor (TKR), which is present in the cell membranes of tissue cells (ligand-receptor interaction) [10]. Therefore, the actual binding site is on the outer surface of the cell membrane and not the cell nucleus. The TKR is a membrane spanning protein that extends into the cytoplasm of cells. After platelet growth factor interaction with the external part of the TKR, activation of inactive messenger proteins will occur in the cytoplasm. Thereafter, the messenger proteins become activated and bind to the TKR cytoplasmic tail. Activated proteins generate via a signaling cascade the cell 
nucleus where it triggers the genes responsible for control of cell division. Thus, transcription of messenger RNA is induced, producing a biological response that starts cascades that provoke tissue repair and tissue regeneration $[11,12]$.

\section{Antimicrobial Activity of PLG}

The fractionated P-LRP is a buffy coat product and contains apart from platelets also a high concentration of several differentiated, nonactivated leukocytes. The white blood cell count has been reported to be two to four times greater in P-LRP than in whole blood [13]. In particular lymphocytes, neutrophilic granulocytes, and monocytes are present in the P-LRP. In an earlier study we could not measure myeloperoxidase levels in the PLG as an indication for leukocyte activation [13]. Therefore, the application PLG of to tissues results in the delivery of platelet growth factors, and potentially, functional leukocytes. Unfortunately, limited data are available addressing the role of the leukocytes in the PLG to act as an antimicrobial component. The neutrophils are known for their host-defense mechanism actions against bacteria and fungi through the actions of myeloperoxidase, present in the neutrophilic granulocytes. Therefore, they play an important role in the immune defense against infections. At tissue sites, myeloperoxidase catalyzes the oxidation of chloride to produce hypochlorous acid and other reactive oxygen derivates. These substances act as potent bactericidal oxidants, and are toxic to microorganisms and fungi [14]. The lymphocytes produce immunocompetent cells and their representative function is found in immunologic defense. The monocytes, precursors for macrophages, produce cytokines and chemotactic factors that participate in inflammation [15].

Furthermore, it has been demonstrated that platelets also contain multiple antimicrobial peptides, which have an antimicrobial effect [16]. Platelet antimicrobial peptides are released after platelet activation, demonstrating potent activities against pathogens that have a tendency to enter the blood stream. Therefore, it is temping to speculate on the antibacterial ability of exogenously applied PLG to tissues. In a recent study of a large cohort of cardiac surgical patients, it was revealed that the intraoperative use of PLG during wound closure significantly decreased the incidence of superficial and deep sternum infections [17]. For these reasons it can be hypothesized that PLG, an engineered biological blood product, has enhanced antimicrobial capabilities, in addition to the effects of the platelet-derived growth factors which might increase wound healing.

Structural Features of Autologous PLG and Surgery

\section{Electron Microscopic Imaging of PLG}

In order to confirm the cell structures in the PLG, and confirm the intracellular platelet changes with the intended release of the platelet $\alpha$ granules, we employed electron microscopic imaging (EMI) at two different stages after P-LRP activation with thrombin.

Venous peripheral circulating blood was drawn from healthy, unmedicated volunteers. The PLG samples for the EMI procedures were prepared according to our standard hospital protocol. Briefly, activated PLG was cut into approximately $1-\mathrm{mm}^{2}$ pieces and placed into a glutaraldehyde $2.5 \%$ buffer solution- $0.1 \mathrm{M}$ sodium cacodylate buffer ( $\mathrm{pH}$ 7.4) for $1 \mathrm{~h}$ at room temperature, followed by a dehydration procedure using graded ethanol concentrations. Thereafter, samples were prepared to be embedded in resin. After polymerization, the plastic was removed. During the cutting procedure, specimen sections were obtained following a semithick $(0.5-\mu \mathrm{m})$ cutting procedure, followed by an ultrathin cutting process to achieve 70-nm sections suitable for EMI.

The objective in the first study was to visualize and determine the total cellular structures of PLG, and to verify the presence of platelet $\alpha$ granules, which contain platelet growth factors. Samples for EMI were prepared exactly 1 min after mixing the P-LRP with thrombin to create PLG. At this stage the clot was viscous enough to be cut and prepared for EMI embedding. In the second study, the same P-LRP activation protocol was followed and the platelet clot was placed in a sterile Petri dish. Due to the activation process, the platelet clot starts to retract and subsequently, clot lysis occurs as demonstrated by fluid built up in the Petri dish, a sign for platelet degranulation. EMI specimens were taken after 20 min of PLG activation.

In the first study, examinations of the specimen revealed a mixture of concentrated and aggregated cells. Platelets were abundantly present, surrounded by granulocytic neutrophils, monocytes, and lymphocytes. Most importantly, all cellular structures were undamaged and the cell membranes of the platelets and leukocytes were intact. Furthermore, fibrin strands were clearly visible in the entire PLG clot (fig. 1A). Inside the platelet structures, $\alpha$ granules were visible, indicating that shortly after PLRP activation, platelet growth factors are still present in the platelet cytoplasm (fig. 1B).

In the second study, after clot lysis had occurred, EMI confirmed the same cell components as in study 1 . However, the platelet cell structures revealed that more than $80 \%$ of the platelet $\alpha$ granules were empty, indicating the

Eur Surg Res 2007;39:199-207 


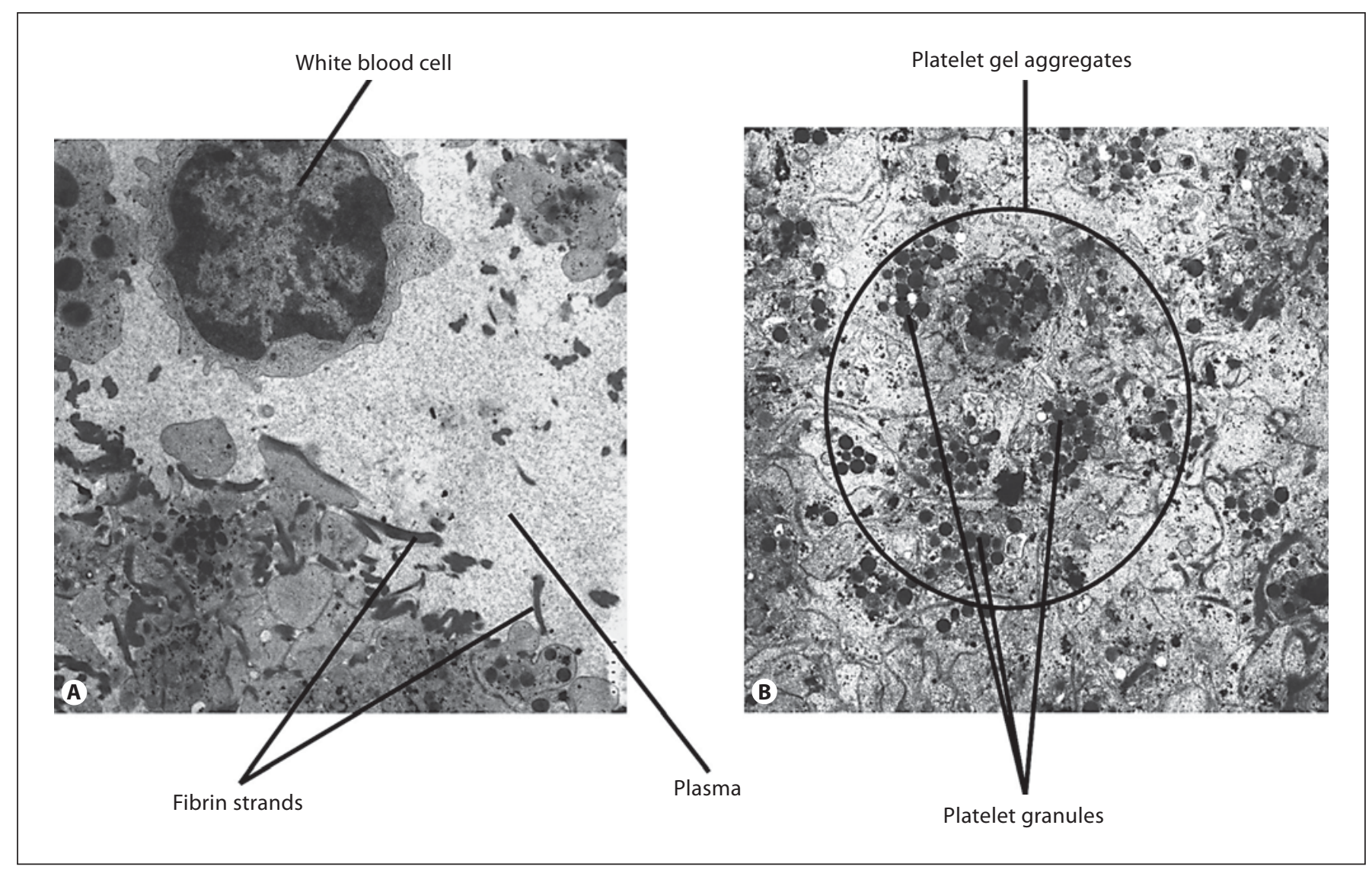

Fig. 1. A EMI of a mixture of platelets, a neutrophilic granulocyte and fibrin strands present in PLG. B Close-up of platelet aggregates with platelet granules inside the platelet structure. Magnification $\times 7,000$.

release of platelet growth factors to the extracellular milieu (fig. 2). Furthermore, and most essentially, the leukocytic cellular structures were undamaged and the cell membranes were intact, also $20 \mathrm{~min}$ following platelet activation. There were only minor signs of leukocytic pseudopodium development.

A closer examination of the granulocytic leukocyte structures revealed the presence of lysosomal granules at magnifications of $\times 7,000$ (fig. 3 ). This finding clearly suggests the presence of a high concentration of neutrophils and monocytes with intact lysosomal granules containing myeloperoxidase.

Our EMI data indicate that the preparation of P-LRP and the subsequent creation of PLG can be performed under controlled conditions without (too early) platelet activation. There was no evidence of platelet activation during the PLG preparation process. This observation is in accordance with data published from an earlier study of our group [13].

\section{Directions for PLG Application}

\section{Wound Healing}

During the wound healing processes, platelet growth factors serve as messengers to regulate a well-orchestrated and complex series of events involving cell-cell and cell-matrix interactions [18]. The repair of wounds and surgical incisions is initiated with the activation of the coagulation cascade, formation of a platelet plug, platelet degranulation, and ultimately the release of growth factors [19]. During the first 2 days of wound healing, an inflammatory process is initiated by the migration of neutrophils. Subsequently, macrophages are attracted to the wound site, were they release multiple growth factors, including transforming growth factors- $\alpha$ and $-\beta$ (TGF$\alpha$, TGF- $\beta$ ), platelet-derived growth factor, interleukin-1, and fibroblast growth factor. Angiogenesis and fibroplasia start after day 3 , followed by the beginning of collagen synthesis on days 3-5 [20]. This process leads to an early 
Fig. 2. EMI showing platelet cell aggregates in PLG after clot retraction has occurred and the platelet granules are emptied in the plasma. Only a few platelets have filled granules.
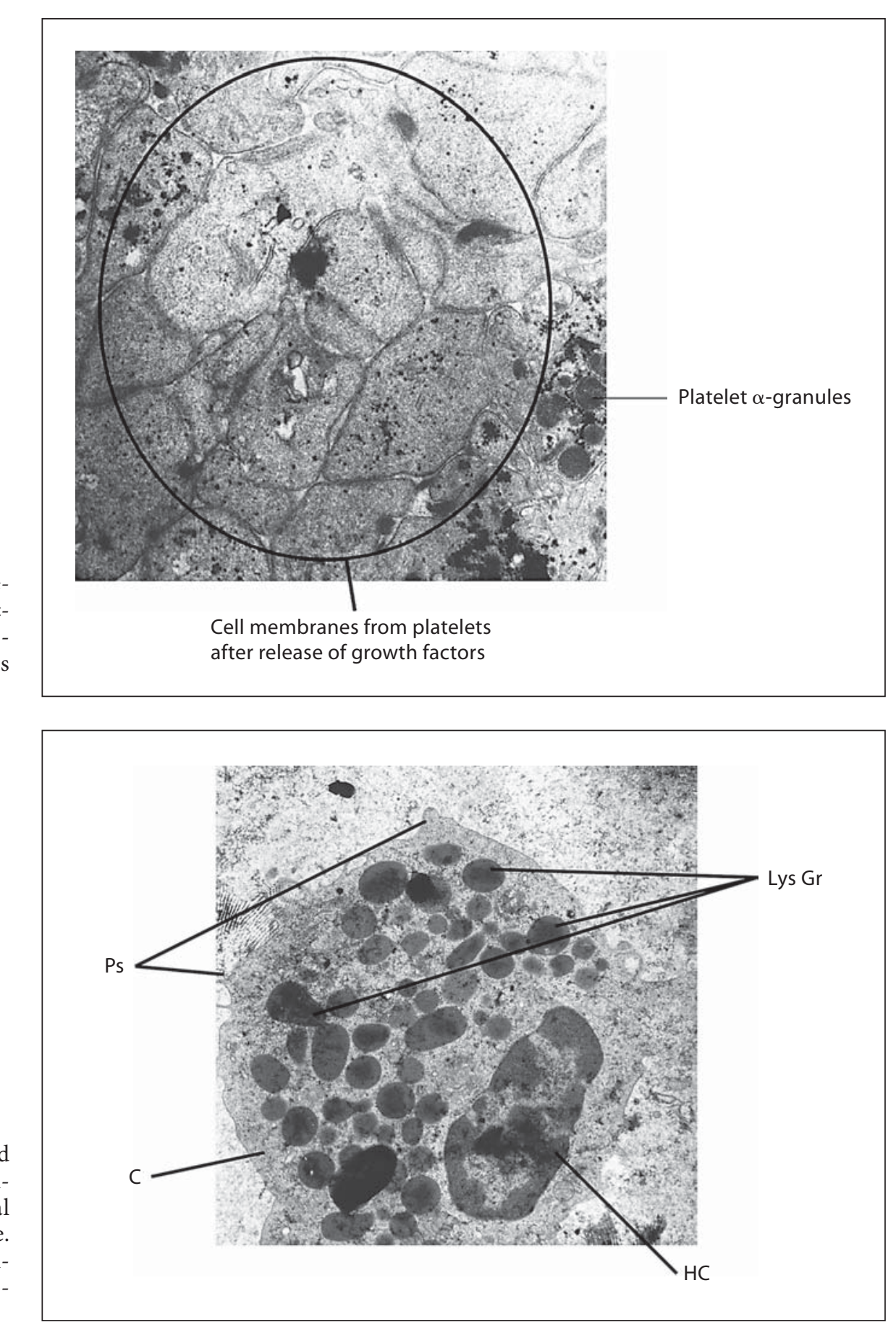

Fig. 3. Magnification of a nonactivated neutrophilic white blood cell, with undamaged cell structures like the lysomal granules, containing myeloperoxidase. Magnification $\times 7,000$. Lys $\mathrm{Gr}=$ Lysosomal granules; $\mathrm{Ps}=$ pseudopods; $\mathrm{C}=$ cytoplasm; $\mathrm{HC}=$ heterochromatin. increase in wound breaking strength, which is the most important wound healing parameter of surgical wounds, followed by epithelialization, and ultimately wound remodeling.

It is generally accepted that platelet growth factors play a key role during the various phases of the wound healing process $[21,22]$. Therefore, the application of PLG to stimulate wound repair is an interesting proposition. Compared to recombinant derived single growth factors, PLG has the advantage that it offers numerous synergistically acting growth factors promoting mitogenesis of mesenchymal stem cells at the wound site $[23,24]$. There- 
fore, topical PLG applications have been performed to treat chronic nonhealing wounds and to support healing after incisional wounds in diabetic patients, who are at risk of impaired wound healing. In chronic wound care management, PLG has been successfully used in patients who suffer from chronic nonhealing and often painful (diabetic) ulcera [25, 26]. Margolis et al. [27] concluded that PLG treatment in diabetic wounds was even more effective in patients with deeper wounds than superficial lesions. In figure 4, a typical PLG application is illustrated in a diabetic wound care patient. Pain reduction following PLG application was observed in a study by Crovetti et al. [28], an effect that is still not understood. In our own experience, we encountered improved wound healing when PLG was applied during wound closure after total knee arthroplasty [29].

In sports medicine, soft tissue trauma (tendon and ligament ruptures), joint capsular injuries and tendonitis occur frequently. Recently, Mishra and Pavelko [30] used PLG in the treatment of chronic elbow tendonitis. Treated patients had less pain and a better function when compared to conservative standardized physical therapy protocols and a variety of other nonoperative treatments. In an Achilles tendon injury rat model, PLG has been used and it was revealed that PLG-treated tendons experienced an approximately $30 \%$ increase in tensile strength and stiffness after the first week when compared to control animals [31]. Anterior cruciate ligament surgery is routinely performed to reconstruct the ligament with an autologous graft. Sanchez et al. [32] reported enhanced healing with less complications and improved fixation of the graft within the bone tunnels in a retrospective clinical trial involving 100 patients when autologous platelet growth factors were used. The reported advanced healing following PLG applications in these soft tissues might be explained by higher concentrations of vascular endothelial growth factor at the tissue injury wound site, which are released from PLG and might promote angiogenesis. Subsequently, blood supply to the injured tendon, mandatory for the tendon repair process, is improved [33]. Future research should provide evidence whether transcutaneous PLG injections, rather than periarticular corticosteroid injections or surgery, could be indicated in the treatment of tendonitis and periarthritis.

\section{Bone Healing}

Impaired bone healing, the development of nonunions following fracture healing, and bone continuity defects cause disability and pain. These circumstances are frequently seen in orthopedic surgery, maxillofacial surgery, neurosurgery, and reconstructive surgery [34, 35]. Traditional surgical treatment consists of autogenous derived bone grafting [36]. The success of bone grafting procedures depends, among others, on the bone healing time for graft host integration [37]. This process involves a variety of biological actions, including an adequate blood supply and availability of an osteoconductive matrix [38]. Furthermore, platelet growth factors released at bone tissue injury sites play an important role in this process since they provide signaling for osteoinduction, through an osteogenic cell response to these signals [39]. Nonetheless, growth factors released from platelets stimulate osteogenesis during the different stages of fracture healing [40,41]. Platelet-derived growth factor has mitogenic properties acting as a chemotactic agent, recruiting mesenchymal stem cells which differentiate at the wound site into osteoclasts [42]. TGF- $\beta$, an important bone stimulatory growth factor, has been suggested to be one of the local regulators of bone formation and resorption [43].

For these reasons, it can be hypothesized that mixing PLG with fragmented autologous bone chips might create an active bioengineered graft, enriched with a high concentration of platelet growth factors (fig. 5A, B). Improvements in bone regeneration time have been observed when platelet-derived growth factor-AB, TGF- $\beta$ and vascular endothelial growth factors were incorporated into bone and other scaffolds [44]. In addition, due to the viscous nature of PLG, the bone chips will stick together during surgical handling, thus avoiding unwanted migration of bone particles. Following clot lysis, the bone chips will no longer adhere to the PLG clot. Another potential application of PLG involves the combination of PLG with different bone substitutes. Several authors have used histomorphometric analysis to demonstrate a beneficial effect of PLG, when different bone matrices were used. Aghaloo et al. [45] used natural deproteinized bovine matrix and observed improved bone growth when this was combined with PLG. Suba et al. [46] used $\beta$-tricalcium phosphate in combination with PLG and found more intense bone regeneration. Recently, PLG was percutaneously applied in a diabetic experimental femur fracture model. Gandhi et al. [47] observed normalized cellular proliferation and chondrogenesis, with an improved mechanical strength, when PLG was injected in this model. Interestingly, Smrke et al. [48] successfully used allogeneic platelet gel to treat a large bone defect. 
Fig. 4. Using a double-syringe delivery technique, PLG is applied to a chronic skin wound. After the first PLG application the wound closed within 4 weeks.
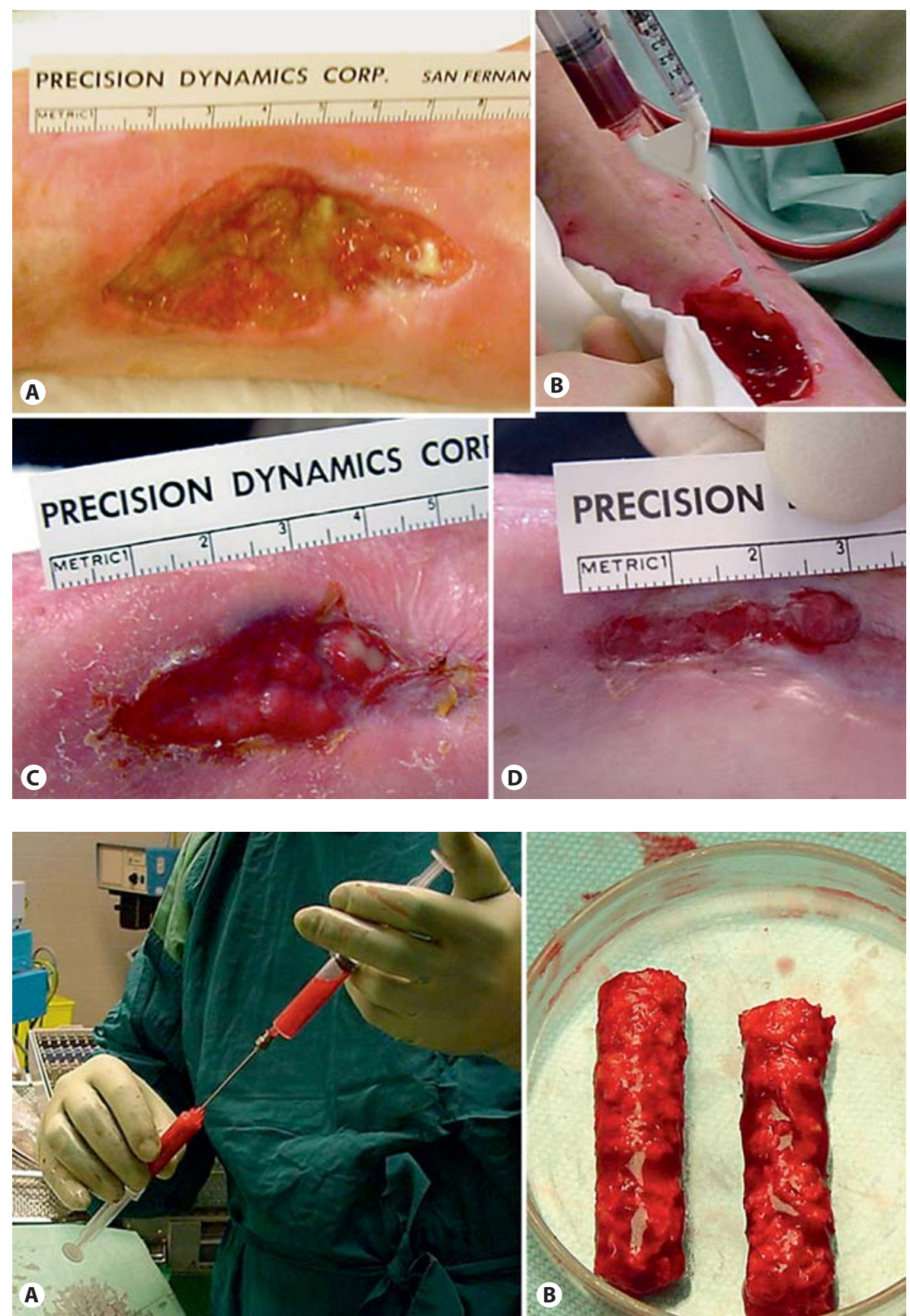

Fig. 5. A Sequestered autologous bone is mixed with PLG. B The results of mixing are shown by the creation of engineered bone grafts, enriched with platelet growth factors.

The use of PLG during autogenous bone grafting might contribute to fulfill some of the requirements needed to increase osteogenesis to stimulate the proliferation of both human trabecular bone cells and human osteoblast-like cells $[49,50]$. Furthermore, the combination of PLG growth factors with bone substitutes might support a more biological healing process and improved bone regeneration.

Structural Features of Autologous PLG and Surgery

\section{Conclusion}

PLG has the potential to become an ideal autologously prepared biological blood-derived product, which can be exogenously applied to a diversity of tissues where it releases high concentrations of platelet growth factors that enhance healing. In addition, it possesses antimicrobial properties that may contribute to the prevention of infec-

Eur Surg Res 2007;39:199-207 
tions. In a previous study we measured the release of platelet growth factors when P-LRP was activated with thrombin [51]. Our EMI data support the release of the platelet growth factors from the $\alpha$ granules when P-LRP is activated. At this moment, the platelets start their structural changes, and growth factors are excreted to the platelet extracellular milieu where they are capable of binding to tissue receptors. It is very important to understand that PLG should be prepared and applied exactly on time. Once the P-LRP has been activated, we believe that PLG, alone or in combination with bone, should be applied to tissues after $1 \mathrm{~min}$. Too early preparation of PLG, with the consequence that the PLG product cannot directly be applied to tissues at the right moment, will result in a significant loss of platelet growth factors. This will most likely result in no positive effects of PLG applications. This might be a reason why there are discrepancies in outcome following PLG applications. Timing is essential to achieve the maximum exposure of platelet growth factors to tissues.

Biological PLG characteristics suggest that it might be a beneficial tool in the surgical armamentarium. PLGs have been successfully used in maxillofacial surgery, orthopedics, cosmetic surgery and dental implantology. However, the procedure to prepare PLG and application techniques are likely to differ greatly amongst clinicians, resulting in inconsistent results. There is also no consensus in the literature on the terminology of the platelet product, as indicated by Bielecki et al. [52]. To avoid conflicting data, standardization of P-LRP methodology is therefore warranted, as pointed out by Borzini et al. [53]. Furthermore, randomized controlled clinical trials are needed to study the effect of PLG in wound rehabilitation, tissue engineering, on bone growth, and clarify the bactericidal effect.

\section{Acknowledgments}

The authors thank Mr. B. Hopman for his support in preparing the sections for electron microscopic imaging and Mr. G. van Dael for preparation of the figures.

\section{References}

1 Hunt TK: Basic principles of wound healing. J Trauma 1990;30:S122-S128.

2 Robson MC: Growth factors as wound healing agents. Curr Opin Biotechnol 1991;2: 863-867.

3 Giannoble WV: Periodontal tissue engineering by growth factors. Bone 1996;19:S23S37.

-4 Weibrich G, Kleis WKG, Hafner G: Growth factor levels in the platelet-rich plasma produced by 2 different methods: curasan-type PRP kit versus PCCS PRP system. Int J Oral Maxillofac Implants 2002;17:184-190.

5 Werner S, Grose R: Regulation of wound healing by growth factors and cytokines. Physiol Rev 2003;83:835-870.

-6 Tabata Y: Tissue regeneration based on growth factor release. Tissue Eng 2003;9:S5S15.

7 Kevy SV, Jacobson MS: Comparison of methods for point of care preparation of autologous platelet gel. J Extra Corpor Technol 2004;36:28-35

$\checkmark 8$ Everts PAM, Brown Mahoney Ch, Hoffmann JJHL, Schönberger JPAM, Box HAM, van Zundert A, Knape JTA: Platelet rich plasma preparation using three devices: implications on platelet activation and platelet growth factor release. Growth Factors 2006; 24:164-171
-9 Marx RE, Carlson ER, Eichstaedt RM, Schimmele SR, Strauss JE, Georgeff KR: Platelet-rich-plasma: growth factor enhancement for bone grafts. Oral Surg Oral Med Oral Pathol Oral Radiol Endod 1998;85: 638-646.

10 Everts PAM, Knape JTA, Weibrich G, Schönberger JPAM, Hoffmann JJHL, Overdevest EP, Box HAM, van Zundert A: Platelet rich plasma and platelet gel: a review. J Extra Corpor Technol 2006;38:174-187.

11 Schliephake H: Bone growth factors in maxillofacial skeletal reconstruction. Int J Oral Maxillofac Surg 2002;31:469-484.

12 Antoniades HN, Williams LT: Human platelet-derived growth factor: structure and functions. Fed Proc 1983;81:2396-2400.

13 Everts PAM, Hoffmann JJHL, Weibrich G, Brown Mahoney Chr, Schönberger JPAM, van Zundert A, Knape JTA: Autologous platelet gel growth factor release and leukocyte kinetics using three devices. Transfus Med 2006;16:363-368.

14 Lincoln JA, Lefkowitz DL, Cain T, et al: Exogenous myeloperoxidase enhances bacterial phagocytosis and intracellular killing by macrophages. Infect Immun 1995;63:30423047.

15 Junqueira LC, Carneiro J (eds): Basic Histology. New York, McGraw-Hill, 2003, pp 97101.
16 Krijgsveld J, Zaat SA, Meeldijk J, et al: Thrombocidins, microbicidal proteins from human blood platelets, are c-terminal deletion products of CXC chemokines. J Biol Chem 2000;275:20374-20381.

17 Trowbridge CC, Stammers AH, Woods E, Yen BR, Klayman M, Gilbert C: Use of platelet gel and its effects on infection in cardiac surgery. J Extra Corpor Technol 2005;37: 381-386.

- 18 Lynch SE, Nixon JC, Colvin RB, Antoniades $\mathrm{HN}$ : Role of platelet-derived growth factor in wound healing: synergistic effects with other growth factors. Proc Natl Acad Sci USA 1987;84:7696-7700.

19 Sixma JJ, Sakariassen KS, Beeser-Visser NH, et al: Adhesion of platelets to human artery subendothelium: effects of factor VIII-von Willebrand factor of various multimeric composition. Blood 1984;63:128-139.

20 McGrath MH: Peptide growth factors and wound healing. Clin Plast Surg 1990;17:421432.

21 Werner S, Grose R: Regulation of wound healing by growth factors and cytokines. Physiol Rev 2003;83:835-870.

22 Lieberman JR, Daluiski A, Einhorn TA: The role of growth factors in the repair of bone. J Bone Joint Surg Am 2002;84:1032-1044. 
-23 Brown RL, Breeden MP, Greenhalg DG: PDGF and TGF-alpha act synergistically to improve wound healing in the genetically diabetic mouse. J Surg Res 1994;56:562570.

24 Kells AF, Coats SR, Schwartz HS, Hoover RL: TGF-beta and PDGF act synergistically in affecting the growth of human osteoblastenriched cultures. Connect Tissue Res 1995; 31:117-124.

-25 Mazzuco L, Medici D, Serra M, et al: The use of autologous platelet gel to treat difficult-toheal wounds: a pilot study. Transfusion 2004; 44:1013-1018.

-26 Henderson JL, Cupp CL, Ross EV, et al: The effects of autologous platelet gel on wound healing. Ear Nose Throat J 2003;82:598602.

-27 Margolis DJ, Kantor J, Santanna J, Strom BL, Berlin JA: Effectiveness of platelet releasate for the treatment of diabetic neuropathic foot ulcers. Diabetes Care 2001;24:483-488.

-28 Crovetti G, Martinelli G, Issi M, et al: Platelet gel for healing cutaneous chronic wounds. Transfus Apher Sci 2004;30:145-151.

$\checkmark 29$ Everts PAM, Devilee RJJ, Brown-Mahoney $\mathrm{Ch}$, et al: Platelet gel and fibrin sealant reduce allogenic blood transfusions and in total knee arthroplasty. Acta Anaesthesiol Scand 2006;50:539-590.

$\checkmark 30$ Mishra A, Pavelko T: Treatment of chronic elbow tendinosis with buffered platelet-rich plasma. Am J Sports Med 2006;34:17741778.

-31 Aspenberg P, Virchenko O: Platelet concentrate injection improves Achilles tendon repair in rats. Acta Orthop Scand 2004;75:9399.

32 Sanchez M, Anitua E, Andia I: Use of autologous plasma rich in growth factors in arthroscopic surgery. Cuader Artroscopia 2003;10:12-19.

-33 Anitua E, Sanchez M, Nurden AT, Zalduendo M, de la Fuente M, Azofra J, Andia I: Reciprocal actions of platelet-secreted TGFbetal on the production of VEGF and HGF by human tendon cells. Plast Reconstr Surg 2007;119:950-959.
34 Luginbuehl V, Meinel L, Merkle HP, Gander B: Localized delivery of growth factors for bone repair. Eur J Pharm Biopharm 2004;58: 197-208.

35 Boehme D, Curtis RJ Jr, DeHaan JT, Kay SP, Young DC, Rockwood CA Jr: Non-union of fractures of the mid-shaft of the clavicle: treatment with a modified Hagie intramedullary pin and autogenous bone-grafting. J Bone Joint Surg Am 1991;73:1219-1226.

36 Sengupta DK, Truumees E, Patel CK, et al: Outcome of local bone versus autogenous iliac crest bone graft in the instrumented posterolateral fusion of the lumbar spine. Spine 2006;31:985-991.

37 Lucarelli E, Beccheroni A, Donati D, et al: Platelet-derived growth factors enhance proliferation of human stromal stem cells. Biomaterials 2003;24:3095-3100.

38 Goldberg VM: Selection of bone grafts for revision total hip arthroplasty. Clin Orthop 2000;381:68-76.

39 Leach JK, Mooney DJ: Bone engineering by controlled delivery of osteoinductive molecules and cells. Expert Opin Biol Ther 2004; 4:1015-1027.

40 Slater M, Patava J, Kingham K, Mason RS: Involvement of platelets in stimulating osteogenic activity. J Orthop Res 1995;13:655663.

41 Bourquie WT, Gross M, Hall BK: Expression of four growth factors during fracture repair. Int J Dev Biol 1993;37:573-579.

42 Schliephake $\mathrm{H}$ : Bone growth factors in maxillofacial skeletal reconstruction. Int J Oral Maxillofac Surg 2002;31:469-484.

43 Rosier RN, O’Keefe RJ, Hicks DG: The potential role of transforming growth factor beta in fracture healing. Clin Orthop 1998; 355:S294-S300.

44 Bames GL, Kostenuik PJ, Gerstenfeld LC, Einhorn TA: Growth factor regulation of fracture repair. J Bone Miner Res 1999;14: 1805-1815.
45 Aghaloo T, Moy P, Freymiller E: Evaluation of platelet-rich plasma in combination with an organic bovine bone in the rabbit cranium: a pilot study. Int J Oral Maxillofac Implants 2004;19:59-65.

46 Suba Z, Takacs D, Gyulai-Gaal S, Kovacs K: Facilitation of b-tricalcium phosphate-induced alveolar bone regeneration by plateletrich plasma in beagle dogs: a histologic and histomorphometric study. Int J Oral Maxillofac Implants 2004;19:832-838.

47 Gandhi A, Doumas C, O’Connor JP, Parsons J, Lin S: The effects of local platelet rich plasma delivery on diabetic fracture healing. Bone 2006;38:540-546.

48 Smrke D, Gubina B, Domanovic D, Rozman P: Allogeneic platelet gel with autologous cancellous bone graft for the treatment of a large bone defect. Eur Surg Res 2007;39:170174.

-49 Gruber R, Varga F, Fischer MB, Watzek G: Platelets stimulate proliferation of bone cells: involvement of platelet-derived growth factor, microparticles and membranes. Clin Oral Implants Res 2002;13:529-535.

50 Weibrich G, Gnoth SH, Otto M, Reichert TE, Wagner W: Growth stimulation of human osteoblast-like cells by thrombocyte concentrates in vitro. Mund Kiefer Gesichtschir 2002;6:168-174.

51 Everts PAM, Brown-Mahoney Ch, Hoffmann JJHL, Schönberger JPAM, Box HAM, van Zundert A, Knape JTA: Platelet rich plasma preparation using three devices: implications on platelet activation and platelet growth factor release. Growth Factors 2006: 24:165-171.

52 Bielecki T, Gazdzik TS, Szczepanski T: What do we use: platelet-rich plasma or plateletrich gel? Bone 2006;39:1388.

53 Borzini P, Mazzucco L, Giampaolo A, Hassan HJ: Platelet gel - the Italian way: a call for procedure standardization and quality control. Transfus Med 2006;16:303-304. 